\title{
TAN REAL COMO LA FICCIÓN
}

\author{
José A. Marín-Casanova \\ Universidad de Sevilla
}

\begin{abstract}
Resumen: Reflexión acerca de la "ficción de la realidad" en el doble sentido del genitivo. La lectura objetiva, predominante en la tradición de Occidente, interpreta la ficción como (un tipo más o menos aparente de) realidad: ficción de realidad. Pero aquí se ensaya la lectura inversa, subjetiva, reforzada por el auge de las nuevas tecnologías, y se interpreta la realidad como un tipo de ficción: realidad de ficción. Así la doble lectura permite repensar la ficción: si nada resulta tan ficticio como lo real, nada resulta tan real como lo ficticio.
\end{abstract}

Palabras clave: realidad, ficción, Ortega y Gasset, artificio, metáfora, nuevas tecnologías.

Abstract: Reflection about the "fiction of the reality" in the double sense of the genitive. The objective, predominant reading in the Western tradition, interprets fiction as (a type more or less apparent of) reality: reality fiction. But the inverse, subjective reading, reinforced by the boom of the new technologies, is tried here, and the reality is interpreted like a type of fiction: fiction reality. Thus the double reading allows rethinking fiction: if nothing is as fictitious as the real thing, nothing is as real as the fictitious thing.

Keywords: reality, fiction, Ortega y Gasset, artifice, metaphor, new technologies

\footnotetext{
"pues la invención, no la copia de realidad, es la verdad en Arte... Todos los hechos y personas de la novela son gratamente imposibles, fantásticos para la realidad..." (Macedonio Fernández)

“nuestra razón se forma sólo por medio de ficciones"(Herder)
}

El Titán era, ya en la intención de sus armadores, además del más rápido y seguro, el mayor navío jamás botado, con dos mástiles propulsados por tres hélices y capacidad para transportar a muchas, más de dos mil, personas. Y, por añadidura, tenía la consideración de insumergible. Esta condición le permitía al coloso un considerable (¿temerario?) ahorro en botes salvavidas ("tan pocos como fije la ley"), la mitad de los necesarios para poder montar a la totalidad de las personas a bordo. La botadura e inicio de su larga singladura inaugural 
tuvo lugar en Southampton, en el mes de abril de hace poco más de cien años. Navegaba a gran velocidad, unos veinticinco nudos, cuando, a los cuatro días de zarpar, encontrándose a unos cientos de millas de Terranova, el buque colisionó con una montaña flotante de hielo. A resultas del choque brutal la nave insumergible perdió definitivamente semejante condición. Se fue a pique y la mayoría de su pasaje pereció en un mar de témpanos.

Esta historia, la de la muerte helada, es muy poco conocida. Es una ficción. Sí, la contó un oscuro escritor, Morgan Robertson, en su novela Futility, or the wreck of the Titan. Muy conocida es, sin embargo, su "réplica" real acaecida catorce años después. También es curioso que en 1892, veinte años antes del infortunio, alguien escribiera un artículo de ficción que trataba sobre el accidente de un trasatlántico que colisionaba con un iceberg. En esta historia, que alertaba sobre la escasez de botes salvavidas del paquebote, los supervivientes eran rescatados por el buque Majestic, que hacía ficticio a un barco real que en aquel momento capitaneaba Edward Smith, capitán que también lo fuera, veinte años después, del Titanic en su único y malogrado periplo. Una fatal casualidad añadida fue que el escritor del referido artículo de denuncia, William Thomas Stead, falleciera en el hundimiento de esa nave.

Claro que no es para tanto la admiración cuando con terminología marina consideramos que "la vida es en sí misma y siempre naufragio" (Ortega 1983b 397). O que, por seguir diciéndolo con Ortega y Gasset, "la vida es darme cuenta, enterarme de que estoy sumergido, náufrago de un elemento extraño a mí”(1981 55). Y lo que el náufrago quiere es salvarse. Y para ello lo que necesita es una tabla de salvación. Y sea de lo que sea la tabla lo relevante es que no es fruto espontáneo de un árbol edénico. Esa tabla no nace como tal, se hace. La naturaleza no produce tablas de salvación. La tabla no es natural, no está dada de suyo, sino que es menester fabricarla. La tabla es artificial, un producto no de la naturaleza, sino de la técnica.

Precisamente nos podemos valer de ciertos aspectos de la meditación orteguiana de la técnica para comprender la relación entre ficción y realidad de un modo no tradicional, de un modo que se cuestione si la distinción que convencionalmente se establece entre lo ficticio y lo real es ficticia o es real. El intelectualismo europeo siempre entendió la relación entre la ficción y la realidad subordinando la ficción a la realidad: sólo la realidad podía justificar (el recurso a y el discurso de) la ficción. La ficción se ha comprendido como ficción de realidad y en el sentido objetivo del genitivo: lo ficticio pertenece de un modo u otro a lo real. Sin realidad no puede haber ficción de la realidad. La sombra de Platón, antonomasia de la metafísica y del más básico de los dualismos occidentales, la bina realidad/apariencias, tiene largas piernas y su proyección focaliza la historia del espíritu europeo. Sin embargo, aquí y de la mano inicialmente de Ortega vamos a convertir la ficción en una necesidad biológica, cultural, intelectual, estética y moral, argumentando que ficción y 
humanización son inseparables. De modo que, lejos de la sospecha platónica, de su mala sombra, que los relega a apariencias ilusorias o a creaciones de mentira, los universos ficcionales no pueden separarse del universo real. Y ello hasta el punto de que sin la ficción no puede haber realidad. Nada tan ficticio como lo "real". Nada tan real como lo "ficticio".

Y es que si bien la ficción no deja de algún modo de ser un tipo de realidad, la realidad no deja tampoco de ser un tipo de ficción ${ }^{1}$, la ficción de esa especie de ficción que es la especie autopoiética, la primera especie real e imposible, la especie humana. Toda vez que nuestra especie, a diferencia de las otras especies, tiene existencia. Ek-siste de todo medio. Quizá por eso dijera Ortega que el humano no se adapta al medio, sino que lo adapta a sí mismo. Esa adaptación (no $a l$, sino) del medio es técnica. De hecho, técnica es creación, y es creación o ficción de un mundo, de un nuevo mundo, distinto del anterior mundo dado. E1 humano finge un mundo porque no pertenece al mundo dado, a la "naturaleza", a la natural realidad. Esa "realidad" no sólo le es extraña al humano, por muy inserto que esté en ella, sino que el ser humano parte filogenéticamente de un extrañamiento, como una anomalía del mundo, primero surgida como algo casual y luego querida como tal anomalía.

Esta anomalía, el extrañamiento del mundo, llevó a nuestro hombre antecesor a un descubrimiento agustiniano avant la lettre. $\mathrm{Y}$ es que el extrañamiento se convirtió en un entrañamiento, en una mirada interior, en un repliegue cuyo resultado es la interioridad del ser humano. Ahí, en la génesis de la hominización está la ficción. El extrañamiento le da acceso al humano a un mundo interior de imágenes, un mundo íntimo de memoria y fantasía. "Este animal que ha entrado en sí mismo es el hombre" (Ortega 1983a 815), el cual no se queda definitivamente sumergido en el interior, sino que a partir de ese mundo interior y sin abandonarlo nunca del todo proyecta un mundo exterior. Y es que el juego de las imágenes permite y exige que el humano tenga que elegir. Y elegir es ejercer la inteligencia, la "eligencia", una inteligencia o elegancia que no se daría sin la ficción que el animal humano elabora dentro de sí: "somos hijos de la fantasía”.

La técnica y sus productos no son, en consecuencia, pese a nostálgicos de una bucólica naturaleza, ninguna novedad adjetiva. La técnica, antes que consecutiva al animal humano, resulta constitutiva. Una naturaleza "real" siempre adversa revela la "minusvalía congénita" de nuestra especie, que precisamente contra tal adversidad, técnica mediante, se rebela. Gracias a la técnica, la especie humana en vez de adaptarse al primer entorno, a la naturaleza, ha adaptado para sí ese

1 "puede acaecer que la verdad sea todo lo contrario de lo que hasta ahora se ha supuesto: que las cosas no tienen ellas por sí un ser, y precisamente porque no lo tienen el hombre se siente perdido en ellas, náufrago en ellas, y no tiene más remedio que hacerles él un ser, que inventárselo. Si así fuese, tendríamos el más formidable vuelco de la tradición filosófica que cabe imaginar" (Ortega 1996 165). 
entorno transformándolo en un entorno nuevo, "ficticio" respecto del primero, el entorno cultural. En este sentido, el humano siempre ha sido un ser artificial en un mundo artificial, un ser ficcional. Su naturaleza, consistente en la paradoja de carecer de ella, lo ha obligado-es, como hemos visto ya, la antropogénesis misma-a dotarse de una "prótesis sobrenatural" con la que suplir el déficit real originario y hacerse su ser ${ }^{2}$. Esa prótesis no se encuentra ahí afuera, en la "realidad", sino que, a su vez, ha tenido que fabricarla. La cultura es la extensión protésica manufacturada de los, por naturaleza poco capaces, órganos humanos. Es, por tanto, el magnífico producto técnico del hombre. Sin embargo, por muy fabulosa que resultase la ficción cultural, la técnica desde la revolución neolítica hasta la segunda revolución industrial ha respondido a la experiencia humana del límite "real". El fictivo mundo artificial de la cultura siempre se correspondía con el infranqueable límite vertical de la natura. Todo artificio, cualquier artefacto, siendo producto humano era educto natural. De ahí que la satisfacción eficaz de la necesidad natural, de lo exigido por la "realidad", fuese patrón canónico de evaluación tecnológica previo a la posterior necesidad humana de eficiencia, validada ésta también según métrica natural. Era, por eso, la correspondencia con la realidad natural lo que permitía determinar la mejor tecnología, el valor de lo artificial: en la naturaleza residía el valor de la técnica, un valor siempre natural.

Aun con el afán de transmutarla, de otorgarle una configuración más benigna para con el humano, la naturaleza ha sido siempre la medida de las acciones técnicas: su fundamento real. En la naturaleza rebotaba toda transformación tecnológica. Desde el mito inicial de Prometeo, "Prometeo encadenado", hasta Frankenstein, el nuevo Prometeo, "Prometeo desencadenado", queda castigado cualquier intento de poner en cuestión el "orden real": el humano, así lo simboliza el mito, tiene mala conciencia por alterar la naturaleza. No puede menos que sentirse culpable de la técnica. Y es que los dioses tenían señalado el límite real más allá del cual no se podía ir. La técnica surgía de la debilidad y la limitación, expresaba la conciencia de lo que no se podía hacer, de la incapacidad, de la "minusvalía". Siempre ha habido, así pues, un límite "lógico" (cosmo-lógico en el mito griego, teo-lógico en la religión judeocristiana, antropo-lógico en el humanismo moderno), un límite que se entendía "real", de lógica natural ${ }^{3}$. En la época del límite natural la técnica era un obrar manipulador de la naturaleza que no llegaba a ponerla en cuestión, la naturaleza era su fundamento o condición de posibilidad. La ficción técnica, transcendida por la realidad natural, nunca alteraba el conjunto de la naturaleza. La técnica no podía llegar a incidir

2 "consistirá el problema en que hay que hacer el ser. ¡Insospechada paradoja! El ser, la "realidad" como algo que hay que hacer. ¿El ser sería entonces... un quehacer? Esto es lo que pasa a todo lo que no está ahí, a todo lo que no hay -que habrá que intentar hacerlo" (Ortega 1986 305-306).

${ }^{3}$ Véanse, con independencia de la valoración, las reflexiones sobre la extralimitación técnica de Galimberti 497 y ss. 
significativamente ni en los grandes ciclos de la naturaleza ni en la historia sagrada ni en la historia humana. Naturaleza, Dios e Historia permanecían ajenos a la técnica, indiferentes e intransigentes en su legalidad natural. El obrar técnico siempre quedaba inscrito en y circunscrito al cerco natural. No había transgresión fehaciente del "orden real".

Y el modelo de la realidad intranscendible, de lo que no se puede transcender porque transciende todo y nos transciende a todos, el modelo de lo transcendental, era la Tierra. Nuestro planeta se ha presentado en el imaginario occidental como la imagen misma de la solidez, de la permanencia, de la estabilidad. Nada más rígido y duro, contundente y duradero que una piedra de toque, antonomasia de la resistencia, excelencia de la substancia, paradigma de la realidad. Y, sin embargo, he aquí que desde que se descubrió la energía nuclear, desde que se comprobó la efectividad de la bomba atómica y desde que la cibernética focaliza toda ciencia permitiendo la extensión ilimitada de las nuevas tecnologías, la Tierra se nos ha hecho líquida. El patrón oro ha encontrado su rey Midas: no sólo es que haya potencia para destruir la Tierra en su conjunto (aunque sólo sea en la superficie que es lo que nos puede importar a los humanos), es que, y los viajes espaciales, como exponente excepcional, y los satélites orbitales, como exponente regular, lo acreditan, estamos en disposición de transcender la Tierra. Le hemos hecho el vacío a la substancia terrestre, la hemos liquidado y, en tanto que canon de poder, la hemos aniquilado. La Tierra, emblema de la "realidad", ya no puede resistírsenos, ya no es nuestro profundo límite.

En efecto, la implosión o contracción ${ }^{4}$ de la tierra en coincidencia con la expansión de la racionalidad tecnológica es el indicativo de la cuasi supresión de la resistencia, de la pérdida de la compensación entre la realidad y la aplicación tecnológica del principio de realidad. Dicho en hipérbole: el cuerpo de la Tierra se ha adelgazado infinitamente cuando el intelecto, hecho naturaleza, ha hecho de la naturaleza intelecto. $\mathrm{O}$ dicho sin tanta prosopopeya: cuando la ha reducido a flujo de información. Asistimos, por seguir con la lupa de la exageración, a la ficción de la realidad. Y en el doble sentido del genitivo: objetivo, pues la realidad se ha hecho ficción: el mundo va cabiendo entero en fórmulas; y subjetivo, pues la ficción se ha hecho realidad: se va formulando un nuevo mundo, un tercer entorno, "sobrenatural"y suprahistórico, virtual. La técnica pesada era proyección fantástica de nuestros órganos, ahora la ligera es la proyección fantástica de nuestra misma fantasía: el entorno digital es totalmente artificial. Lo que, a su

\footnotetext{
${ }^{4}$ Esa contracción (o "eterealización" o libertad respecto de un medio más material, por decirlo con Toynbee 188-189) se expresa paladinamente en el hecho de que el hardware se haya venido a transformar en software y el software se esté transformando, como suele decir Nicholas Johnson, en mindware, o en el hecho de que la digitalización signifique que es posible traducir cualquier conjunto de inputs en cualquier conjunto de outputs, vale decir, que cualquier contenido puede almacenarse en cualquier soporte o transmitirse por cualquier medio. Lo que, categorizado hegelianamente, supone que la materia ha sido transmutada en "espíritu" por la tecnología: lo real natural está en función de lo ficticio tecnológico.
} 
vez, significa que, habiéndonos incorporado la naturaleza a lo largo de la historia (la natura - en lo que respecta al humano- es absorbida por la cultura), toda la Tierra se ha hecho casi extensión de nuestro cuerpo, y éste, casi una extensión de la tecnología (la cultura va siendo absorbida por la cibercultura). Y esto es un novum metafísico, una realidad jamás dada antes.

No parece que nadie pueda poner en duda que estamos ante una novedad cualitativa $^{5}$, en la edad tecnológica. Antaño, en la época del límite natural, la técnica se limitaba siempre a la naturaleza, la cual, en último término y en todo caso, presentaba una resistencia insuperable. En cambio, en la época de la ilimitación técnica, y de manera exponencial con el auge y propagación de las teletecnologías, el panorama aparece transmutado: asistimos a la disolución de la resistencia, al debilitamiento del ser o aligeramiento de la naturaleza, y, por tanto, la conciencia del límite natural, real, se ha desdibujado, la limitación aparece tan difuminada que el humano se siente más allá de ella, capaz de fingir el transcenderla. El poder de la ficción técnica, de la experimentación tecnológica, perdida la estabilidad natural, se muestra sin límites y eso abre un nuevo horizonte: el de la experimentabilidad ilimitada y la manipulabilidad infinita en una Tierra real que se ha revelado contingente ${ }^{6}$.

Otrora, del "ficticio" límite natural tomado por real dependía la praxis artificial. Pero ahora la naturaleza no es el prius de la técnica, su necesidad ya no es, como quería el Prometeo encadenado (v. 514) de Esquilo, mucho más fuerte que la técnica, sino que se ha perdido la ecuación compensatoria entre la técnica y la naturalidad del hombre, hasta el punto de que no sólo ésta sino que toda la naturaleza empieza a dejar de ser independiente del hombre: actualmente - recuérdese el dictum orteguiano- los supuestos técnicos de la vida pesan más que los naturales. Hoy la "extralimitación" técnica pone al hombre frente a un mundo como disponibilidad cuasi absoluta, y así la naturaleza humana, ya no puede ser pensada como antes, como naturaleza, como naturaleza racional.

${ }^{5}$ Sin menoscabo de que nibil novum sub sole, de que el humano siempre ha sido técnico, incluso cuando más invocaba el hierocratismo natural, en tanto que proceda distinguir entre entornos, procederá el énfasis en la novedad, pues las TICs han liquidado o fluidificado toda la Tierra (por no hablar de las biotecnologías que han hecho que ya no se pueda separar radicalmente el artefacto del-por emplear la denominación de Manuel Pavón-"biofacto"). La Tierra ha perdido toda sacralidad, su condición de límite de la experiencia humana, y se ha hecho corriente, corriente eléctrica. $\mathrm{Y}$ eso ha producido en el humano un correspondiente novedoso azoramiento por la "conciencia de su principal ilimitación", por decirlo con Ortega (1964 366). Ya no es la naturaleza, sino la técnica el horizonte de la autocomprensión humana.

${ }^{6}$ Si ya no hay límites naturales, sólo cabrá la autolimitación técnica: en un universo tecnológico, en el que lo natural está absorbido en lo técnico, como función suya, la naturaleza entra como objeto de la responsabilidad moral. De hecho, es plausible la ficción de un acercamiento a la comprensión de lo axiológico como técnica inhibitoria: sobre la base del instinto de supervivencia, valor primero de la técnica, se ensayará la consideración del valor como técnica. Aunque éste no sea exactamente su planteamiento, merece reconocerse aquí el feraz esfuerzo de Jorge Riechmann, entre nosotros, por reivindicar la autolimitación. 
Parece que la naturaleza humana ya no puede ser pensada, cuando ya se habla del sobrehumano, del transhumano o incluso del posthumano. A éste habrá de corresponderle una nueva racionalidad ya no "real", una razón retórica. La disolución del mundo metafísico, el desfondamiento de la vieja naturaleza real, va acompañado del de sus categorías racionales. Y es que si ya había algo de distal en las tecnologías más rudimentarias, las teletecnologías han logrado distanciar máximamente al humano tanto de la naturaleza como de una razón natural. La paradoja de la técnica, esa que consiste en sacar el mundo exterior desde el interior humano, se ha agigantado con las nuevas tecnologías, ya que éstas están provocando ahora que sea nuestra imaginación la que desde fuera nos mire, y esto necesariamente nos obliga a cambiar la percepción de nosotros mismos: no sólo nuestro qué sino a su vez nuestro quién. Es decir, que sea el exterior, el imaginario exterior el que configure a la especie, que la naturalidad humana sea tendencialmente el sostén de los aparatos protésicos, que lo orgánico vaya siendo poco más que el soporte de lo mecánico, que la biología se metamorfosee en percha de la tecnología, que el cyborg, el humano biónico, no sea una hipótesis de ciencia-ficción, sino de ciencia biotecnológica, todo ello, demanda una nueva racionalidad con que expresarlo ${ }^{7}$.

$\mathrm{Y}$ el primer dato que habrá que tener en consideración es el vaciado de lo natural que ha operado nuestra especie. Por un lado, hemos vaciado de contenido a la naturaleza; y, por otro y a la par, nos hemos vaciado de naturaleza. En efecto, hemos desnaturalizado la Tierra, con lo que la realidad natural se ha desfondado y desestabilizado, y así, se nos ha derrumbado el gran teatro en el que discurría la obra humana en el tiempo, la historia de la cultura, que presuponía una Tierra permanente y segura. Y ello con la paradoja final de que sea la aplicación del "principio de realidad" lo que ha acabado con la "realidad". La técnica buscando la máxima fidelidad a lo real nos devuelve nuestra imagen, nos revela la virtualidad de lo real: el mundo verdadero se ha hecho fábula. La pérdida del sentido general del ser natural que constata la tecnociencia en la universal objetivación del ente, el fin de la "metafísica de la presencia" en las teletecnologías, ha terminado produciendo la fabulación del mundo, que la realidad se haga vaga, que adquiera los perfiles de lo fantástico, de lo fictivo ${ }^{8}$. Y

7 Cf. Vega. Del panorama internacional, como defensores recalcitrantes, bien que diversos en sus enfoques, de la "naturaleza humana", se puede destacar a Fukuyama y a Pinker. Y sobre el problema de cómo la modificación tecnológica de la naturaleza humana afectará a la autocomprensión ética de la especie, con un planteamiento diametralmente opuesto a la "antropométrica" de Sloterdijk, véase Habermas.

8 "El desarrollo del mundo científico-técnico, en la forma de mundo de la información generalizada y del consumo de masas, muestra la tendencia de la realidad a disolverse en la vaguedad de lo poético" (Vattimo 1990 42). La realidad se ha aligerado, ha perdido peso y densidad, objetividad en el proceso de objetivación del principio de realidad. Éste es el resultado de la experiencia no-velada de la realidad: la sustitución afirmada por Rosen de la naturaleza por las poesías. El yo, en consonancia con la adquisición de un contorno novelesco por el mundo, 
este desvanecimiento o desmayo de lo real es un desafío para la razón, que ya nunca más podrá pretenderse natural.

En efecto, para sostener con "razón natural" que la verdad es anterior y exterior a su expresión lingüística, es necesario, lo que no es obvio en manera alguna, presuponer una correspondencia no problemática entre la interpretación y su referente, entre la proposición y la "realidad", y así poder comprobar esa correspondencia. Con lo que, de un lado, la realidad tendría que ser estable y autosubsistente, autoidéntica, habría un referente único y unívoco, y, de otro lado, la percepción de ese referente sería directa y neutra, "objetiva”, pues accedería neutralmente al propio referente. La contemplación, entonces, permanecería separada de lo contemplado y habría que admitir que tenemos lo que Berlin llamaba el "ojo metafísico", o Putnam la "perspectiva del ojo divino". Y esto es demasiado suponer.

Ciertamente, antes de presumir una realidad dotada de una estructura unificada, atemporal e inmutable, eterna, de la cual una lógica perfecta pudiera dar una descripción perfecta, inmediata y directa, no influida por la propia circunstancia de tiempo y espacio del descriptor, antes de presuponer lo que William James llamara la "édition de luxe del universo", lo cual obliga a duplicar el mundo, poniendo tras el mundo de nuestra experiencia fáctica un fundamento o posibilidad de la misma, es decir, presuponiendo una edición real, definitiva, "completa para siempre" del mundo y luego las "distintas ediciones finitas, plagadas de falsas lecturas, distorsionadas y mutiladas cada una a su manera" (206), antes de cargar con semejante cúmulo de presuposiciones teletecnológicamente insostenibles es preferible la elección de aquella explicación que no niega tener presupuestos, pero que afirma tener menos presupuestos que la que niega tenerlos, es preferible la opción más sencilla, más simple, y más económica.

Es menos agradable, menos tonificante, menos consolador aceptar la soledad del hombre en el universo, su deficiencia congénita, su minusvalía constitutiva, su desvalimiento permanente, pero a menos que adoptemos arbitrariamente un wishful thinking, es mejor atenuar esa fortísima reclamación "theórica" de sentido enfático del universo, una petición no innata, sino inducida, una petición de principio, y abandonando el emplazamiento de privilegio del hombre en el cosmos prescindir de la suposición de la separación entre conciencia o mente y cuerpo, paralela a la de mente y realidad, una mente y un realidad que, no obstante, se presuponían como hechas la una para la otra, y reconocer pragmáticamente que lo que sea la verdad, la hacen a la vez mente y cuerpo, que, como muestra el miedo, son la misma cosa.

por decirlo con la célebre expresión de D. Dennet, se metamorfosea en un "centro de gravedad narrativa”. 
En efecto, se trata de reconocer lo que Hans Blumenberg ha llamado el "absolutismo de la realidad", vale decir, la desconsideración y prepotencia de la realidad respecto del ser humano o, visto desde el otro lado, la soledad humana respecto de un universo mudo de sentido. La indiferencia de lo real ante lo humano marca su absolutez. Una absolutez que indica el carácter refractario a todo sentido, meta o propósito que posee la realidad naturalmente entendida. No cabe un fundamento en un mundo inconmensurable, mudo e indiferente como es el universo copernicano: la realidad es absolutamente contingente. El cosmos, presentado por la ciencia como una mezcla de helio e hidrógeno, no transmite ningún contenido significativo, ningún mensaje a la humanidad, la cual, por tanto, se encuentra presa en el cerco de la mayor de las soledades posibles. Y es la historia de la humanidad, la historia de la gente, la expresión del esfuerzo por escapar a esa espantosa soledad, por mantener a distancia la soberanía de lo real, por ponerse a salvo del absolutismo de la realidad. La técnica (como el mito, la religión o la metafísica) constituye el instrumento substantivo con el que romper esa tiranía de la naturaleza para introducir sentido en lo que de suyo no lo tiene, para hacer hablar a lo eterno silente, al avaro silencio del desierto de los espacios siderales, para construir un mundo de palabras llenando de ficticio sentido terrestre el real vacío celeste. Eso es, a mi juicio, la "ficción" de la técnica: la casa del hombre, su hogar en medio de lo inhóspito. La técnica es, como decía Ortega en su Meditación, la "reforma de la naturaleza" (324), la "adaptación del medio al sujeto" (326), el "esfuerzo para ahorrar el esfuerzo" (333). Y es que no se puede entender la técnica como ficción, sino como la respuesta humana a la opresividad de la contingencia, cuya función es la de aliviar el terror para hacerle sentir al hombre en casa.

Así, ante la inconmensurabilidad entre el tiempo físico y el tiempo humano, ante la temporalidad cósmica que en comparación con la temporalidad vital presenta una desproporción descomunal, cifra del desamparo del hombre, habitante efímero de un planeta pasajero, cuya duración no es más que un mínimo instante para la del inmenso mar sin sentido en el que naufraga, los humanos nos rebelamos, y técnicamente fingimos, frente al poder absoluto del tiempo cósmico, un mundo de la vida, el cual nos brinda una playa tranquila, campana protectora, donde, por merced de la cómoda confianza en las cosas cotidianas, se puede conseguir algo de la discreta seguridad del hogar.

Así, frente al mundo inhóspito y brutal, naturaleza fría y despiadada, la "cueva ficcional" de la técnica nos distancia de esa crueldad del afuera ofreciéndonos amparo y cobijo, calor y protección, evasión de la ofensiva y degradante realidad.

${ }^{9}$ La noción de Absolutismus der Wirklichkeit (cf.Blumenberg 1996a 9), de la nimiedad y futilidad del hombre dentro de una realidad muda e indiferente, junto con sus previos "heterónimos" (absolutismo teológico, absolutismo del libro, absolutismo del tiempo cósmico, absolutismo de la metáfora) es clave de lectura de todas las obras mayores de H. Blumenberg, en cuyas ideas encuentra inspiración buena parte de lo que aquí se está sosteniendo (cf. Marín-Casanova 2007). 
La caverna técnica es sinónimo de espacio de seguridad y orientación, la metáfora de todas las costumbres, tradiciones e instituciones, es decir, de la cultura. A diferencia de los griegos, que creyeron que el origen de la forma humana de vida es la gruta, imaginemos a los hombres no surgiendo de las profundidades subterráneas, sino de los espacios abiertos, de cuyos ataques mortales huyen en pos de otra realidad, que les haga más llevadera la vida, de otra realidad a cuyo abrigo poder sacudirse el miedo al mundo exterior y, en el límite, al propio mundo exterior, suplantando entonces la realidad ajena por una realidad propia, la realidad natural por una realidad fictiva, la "troglodita".

Una realidad propia, de apalabras propias, apalabrada, una realidad “verdadera”, verdaderamente humana, donde se considera verdadero a lo más conveniente, lo más beneficioso para nuestras vidas. La verdad "cavernícola", la verdad "ficticia", viene a ser una especie de lo bueno, lo que para nosotros es mejor creer, por parafrasear a James, que nos previno de la verdad "celeste", que no sirve para nada, y que nos enseñó que la verdad, como Vico proféticamente fabuló, no se descubre, sino que se hace: verum ipsum factum. El hecho no es verdadero, simplemente es. Es la verdad la que es hecho, la que es hecha; la que es hecha como aquello que nos permite integrar las nuevas experiencias en las pasadas, las experiencias con las que vamos logrando la unión del mundo, aunque siempre permanezca múltiple, plural, porque no hay conexión que no sea parcial o que no falle.

El conocimiento, ya no contemplativo, sino operativo, se presenta así como un tipo más de acción, como un conjunto de instrumentos, como una herramienta, una técnica con la que no copiar una realidad de la que no nos podemos salir, en la que estamos necesariamente atrapados, sino para establecer una serie ficticia de relaciones con el mundo "real", con ese mundo inestable y plural, que sólo conocemos tangencialmente, mediante metáforas: la referencia humana a la realidad es indirecta, prolija, diferida, selectiva y, por encima de todo, metafórica (cf. Blumenberg 1996b 115).

Por medio de la técnica, una técnica que es a lo material lo que la metáfora a lo intelectual, una técnica que es a la metáfora lo que el concepto a la ciencia, no retratamos lo real natural, ni en ardoroso amor a la verdad lo poseemos "theóricamente", sino que nos distanciamos de él, nos protegemos de él, pues antes que el amor (y que la curiosidad o la admiración) estuvo el terror y el temor. Y el temblor (lo sagrado se venera temblando). Y al igual que el mito con sus muchos dioses repartió el poder para relativizarlo (cf. Marquard 91-116), la razón técnica, mítica, fabulosa o "ficticia", se abre camino no como capricho casual, sino impulsada por una necesidad acuciante, por el hostigamiento de la faz absoluta que revela la realidad contra la que con su ficción se rebela. Ésa es la razón de la ficción de la técnica y de la técnica de la ficción: intentar romper con la dependencia absoluta de la realidad natural (cf. Marín-Casanova 2007 y 2009). La razón técnica no es un poder anónimo, sino un desarrollo fabuloso del espíritu racional al mítico servicio de la supervivencia humana-éste es 
el valor, no el conocimiento-, para seguir manteniendo a distancia, no para dominar-la realidad nunca se deja dominar, velis nolis, hay que obedecerla siempre-, el poder absoluto de la realidad y así disipar su horror, creando la ficción de un mundo sólito, de violencia domesticada, de desnudez vestida, un mundo humano, un mundo nuestro, nuestro mundo.

Y si esto es así, si la realidad o naturaleza es indiferente a nuestros valores, si el valor es cosa humana, siendo el hombre a su vez no una conciencia originaria, fundante o constituyente, sino, antes bien, resultado naturalmente técnico, artificio, si, en consecuencia, la distinción entre ciencia y técnica es artificial, también es artificial la distinción entre lo natural y lo artificial: toda realidad humana es realidad artificial, virtual, ficcional. Esto ha de derivarse de todo lo que antes se ha estado señalando. Sólo desde una posición clásica, "objetivista”, que presuponga que hay un significado al margen de la intervención humana, un significado descarnado, independiente de nuestra categorización o recorte de lo real, propiedad de los objetos considerados en sí mismos, esto es, como algo objetivo, independiente de su uso, puede sostenerse que entonces afirmar que todo lo humano es ficcional supone "caer" en un "subjetivismo relativista" y éticamente en el cinismo del "todo vale". Pero es que uno sólo puede ser "subjetivista" si implícitamente acepta las reglas de juego del "objetivismo"; aun cuando sea con el subversivo propósito de quebrantarlas, las requiere como el pecador morboso, que perdería el placer que le proporciona su culpa, si recusase la tipificación de su conducta como pecaminosa. Ciertamente, el subjetivismo se ve como alternativa al realismo, una alternativa vindicativa de los elementos reprimidos por la objetividad, en tanto que apología de la emoción, la pasión, la voluntad, el instinto, y qué sabe uno mientras sea "irracional". Ahora bien, formal o estructuralmente obedece a la misma lógica metafísica del objetivismo, sólo cambia-lo que, por otro lado, pero no el que aquí interesa, no es pocola valoración del contenido. En efecto, la posición "romántica" como también podemos recalificar al subjetivismo, aun cuando valora positivamente todo lo que denuesta el "realismo", implícitamente está aceptando el recorte racionalista de la razón, el reduccionismo de lo racional a lo "objetivo", le está dando en su reivindicación de la sinrazón—he ahí la tosquedad de todo esprit de finessetoda la razón al realismo racionalista, al objetivismo.

El mito retórico-hermenéutico, por el contrario, en lugar de alinearse en uno de los flancos de la cesura metafísica ora en el de lo real, lo natural, lo único, lo literal, lo conceptual, lo lógico... ora en el de lo ficticio, lo virtual, lo artificial, lo múltiple, lo literario, lo metafórico, lo mítico..., como llevan a cabo, respectivamente, tanto el mito objetivista cuanto el subjetivista, lo que hace es denunciar el carácter monodimensional, monológico, monomítico de esos dos mitos tradicionales, el clásico (hipertrofiado en su mojón ilustrado ${ }^{10}$ ) y el

10 Este "mito" se vendría a hacer eco de estas voces de Marc Petit: "En nuestros días, el mito goza de peor reputación, sobre todo en los medios intelectuales. Se le reprocha que miente, que es 
romántico, y, por tanto, ir más allá de la cesura misma, no reconocerla como "real" (cf. Marín-Casanova 2004) No se trata, así pues, de invertir los términos del binomio metafísico, de poner ahora en el lado de lo real, de lo natural, de lo único, de lo literal, de lo conceptual, de lo lógico, lo artificial, lo múltiple, lo literario, lo metafórico, lo mítico..., sino de caer en la cuenta de que, desaparecida la noción de "real", también desaparece la de lo "ficticio": no es que lo ficticio derroque a lo real, sino que, sin un real respecto del que serlo, lo ficticio deja de ser lo meramente ficticio.

Cuando se afirma que toda realidad humana es "ficticia", nos traiciona el lenguaje, un lenguaje que no puede desprenderse sin más del lastre milenario de la tradición metafísica, pero ha de repararse en que no se trata de desplazar y sustituir lisa y llanamente el lugar de lo real por el de lo ficticio ${ }^{11}$ (o paralelamente de reemplazar la razón por la sinrazón), sino de asumir que en las cosas humanas desde siempre lo real era "ficticio" porque lo ficticio era "real", que ambos términos eran dos caras jánicas de lo "mismo" (en este sentido el transhumano del que se habla hogaño no es tanto algo porvenir, sino que siempre fuimos transhumanos). Por supuesto que sigue siendo psicológica y moralmente necesario, una necesidad de la vida, acaso el único transcendental verdadero, distinguir planos que se corresponden con lo que en la tradición metafísica era la distinción realidad/ ficción, pero ahora sabemos que esa distinción no es fuerte sino constitutivamente débil (¡no es real, sino “ficticia”!), que por lo demás en esa su debilidad artificial reside su fortaleza: justa y paradójicamente lo que otorga valor a los valores es su falta de "valor real" (natural), su realidad puesta, la ficción del valor.

En el tiempo en que había "realidad": el mundo era sólido, estaba lleno de objetos o presencias reales ante un sujeto también real. Pero de ese mundo casi nada queda. Las nuevas tecnologías se han encargado de su vaciamiento.

solamente una fábula, una pamplina. Desmitificar, desmistificar se considera una acción saludable, en la línea del miserabilismo puritano que está causando estragos en todas partes [...], pues con bastante frecuencia he creído detectar, entre personas de buena fe, un extraño malestar en cuanto pronunciamos estas palabras tabú: mito, fábula, leyenda, cuento, e incluso imaginario... y ficción" (45-46).

11 "La ficción está más allá de lo verdadero y lo falso", afirma Genette bajo el rubro "Les actes de fiction" (1991 20). Y es que cuando, según el célebre dictum de Nietzsche, "el mundo verdadero, por fin, se hizo fábula" no es que la fábula se haga verdadera sin más, esto es, "real", sino que la distinción entre la realidad y la ficción se "des-realiza". "En las ideas nietzscheanas de nihilismo y "voluntad de poder" se anuncia la interpretación de la modernidad como consumación final de la creencia en el ser y en la realidad como datos 'objetivos' que el pensamiento se debería limitar a contemplar para conformarse a sus leyes" (Vattimo 1996 23-24). Es decir, la realidad del mundo, que ha acabado en ficción, es la realidad que primero fue platónicamente en un más allá metafísico y luego kantianamente se descubrió co-constituida por la intervención del sujeto, intervención que posteriormente va a llevar a que se la identifique con lo que viene producido por la tecnociencia: no hay "realidad" (verdadera) cuando la verdad se reduce a lo "puesto" por el hombre, a su voluntad de poder. Y en esto, que la realidad sea producto del sujeto, es lo que, desde el punto de vista de Heidegger, estriba precisamente el nihilismo. 
Ya no hay quedar, la vieja permanencia substantiva ha cedido su lugar a la fugaz eventualidad. Ya es corriente el fuego de Heráclito, la corriente eléctrica que todo fluidifica: la energía es el acto puro que ha liquidado la resistencia natural. He ahí la paradoja: cuando triunfa, merced a la técnica, el principio de realidad, la realidad queda debilitada y su recuperación ya sólo puede ser virtual. Ciertamente, cuando la "realidad" es ficción el principio que la exponga ya no puede ser otro que un principio de artificialidad o de fabulación, un principio fabuloso, porque no es ningún principio. Y este es el valor de la técnica: habernos dejado un mundo sin fondo, desfondado, sin fundamento. Ante este desmayo de lo real cabe, en primer lugar, una actitud de nostalgia, de restauración de la realidad perdida, un sentimiento, o mejor sea decir, un resentimiento de pérdida. Las mentalidades tecnófobas arraigan ahí, la derrota de la naturaleza a manos de la técnica les parece el mayor de los disvalores, un oprobio que reclama venganza: la re/vuelta de/a la naturaleza. En cambio, esa situación de desplome técnico del fundamento natural puede ser entendida en términos de oportunidad gozosa, como un valor, un valor que exige mucho valor, el de "sustituir" lo sólido por lo solidario, el principio de razón suficiente por el de "razón insuficiente", lo real por lo ficticio, reconociendo que la naturaleza no nos proporciona ninguna coartada para nuestro obrar y que, por consiguiente, el aval de nuestra conducta habrá que construirlo, que hacerlo corriente. El valor de la técnica estriba entonces no ya sólo en la técnica como valor, un valor neutro en tanto que la razón técnica, en su dimensión primaria de respuesta al estímulo en aras de la supervivencia, la compartimos, aunque obviamente en distinta medida, con los extremófilos y los primos primates, un valor neutro a fuer de necesario o automático, sino en el valor como técnica, una técnica en cuya razón están presentes los demás, cuyo valor no es la supervivencia orgánica, la vida, sino la supervivencia de una formalización determinada de la vida humana (la adaptación al otro "medio" ambiente, al medio cultural), la buena vida, un valor interesado a fuer de libre o sintomático. Los valores, en efecto, no pueden ser descubiertos, no son naturales, sino que, en tanto que ficciones, han de ser inventados. Los valores, ficcionales todos ellos, siendo principales no son "principiales", sino fácticos: hay que creerlos y par pari crearlos. Por eso se requiere tanto valor, porque se trata de una técnica que como tal es contingente, sin fundamento que la soporte más allá de la voluntad "insuficientemente" racional de emplearla.

$\mathrm{Y}$ es que la técnica como valor, el valor neutro de neutralizar la naturaleza para así figurarse o fingirse el humano una naturaleza, un valor éticamente neutro o desinteresado en tanto que sirve al interés meramente genérico de la supervivencia, del mantenimiento de la vida humana, que es posibilidad misma de la humanización, es indesligable ${ }^{12}$ del valor como técnica. Pues si bien es cierto

${ }^{12}$ La técnica como valor al servicio de la supervivencia es neutra en tanto que no predetermina una moral determinada, aunque sí la moral. No hay por qué ligar los valores a ninguna naturaleza 
que la formalidad técnica "por sí misma no nos ayuda a decidir a qué especie o a qué cultura sería mejor pertenecer" (Rorty 1998 81) y por ello hablamos de su neutralidad, resulta que los humanos nunca nos encontramos existiendo en la mera formalidad, en la abstracción de la supervivencia de la vida, sino siempre en busca de la buena vida ${ }^{13}$. Y ahí ya no cabe hablar de la neutralidad del valor de la técnica, del uso automático de la técnica para sobrevivir, pues aunque lo incorporemos como automatismo, el empleo de la técnica nunca fue neutral, el inicio de una técnica nunca es automático, sino sintomático, y según la técnica empleada así ha sido la vida que se ha vivido. Gracias al valor de la técnica en el sentido genitivo objetivo, que ha vaciado a la naturaleza, un valor que en abstracto se presenta como neutral en tanto que condición de la especie, nos damos cuenta de que ese valor nunca es concretamente neutral: la técnica ya no la podemos pensar como neutral respecto de la propia naturaleza humana, precisamente porque sabemos que no se da la naturaleza humana en superlativo singular, sino que la naturaleza humana se modifica según la declinación técnica, se fabrica. $Y$ entonces no podemos separar nunca de la experiencia histórica humana el valor objetivo de la técnica del subjetivo, la técnica como valor del valor como técnica.

Y ello máximamente en nuestros días porque sabemos que la fuerza de la técnica actual es tanto constructiva como destructiva, tiene potencial de sobra para aniquilar la totalidad de la superficie del planeta. Cuando había historia, el humano tenía sus posibilidades de autorrealización y sus abismos escritos previamente, prescritos en la naturaleza, la existencia se resolvía en la conformidad con la naturaleza. Hoy somos conscientes de que esas posibilidades están inscritas en la técnica y la existencia depende de la capacidad técnica de autorregulación (Galimberti 49-86) La técnica modifica la naturaleza del hombre, porque disloca el horizonte de su autocomprensión, que estriba ya no en conformarse a la naturaleza, sino en la capacidad de autolimitación del poderío tecnológico. La técnica aloja un inmenso potencial de vida al que es paralelo el potencial de muerte, y la respuesta no nos la puede dar una extinta realidad natural, sino la propia técnica. No en el sentido de la técnica por sí misma, como abstracción neutral, sino en el sentido de que la respuesta no sólo no puede preterir la técnica, sino que habrá de substanciarse técnicamente. El valor interactúa con el mundo de la técnica, pero no en el nombre de una naturaleza real, sino como una técnica ficcional: no se trata de escoger entre la

ni física ni metafísica, a ningún cosmos ni a ningún cielo, pues en el mismo afán de supervivencia se puede ver el origen de la moral, situándola así en continuidad con la biología. De este modo, sobre la raíz biológica de la moral, se pronuncia Scalfari: "l'istinto di sopravvivenza della specie è il fondamento della morale. È quell'istinto che detta le regole, è da esso che promana la necessità della legge, è la sua volontà che determina i comportamenti. La ragione entra in gioco per scegliere i modi più efficaci affinché quell'istinto produca i voluti effetti" (92).

13 "Y precisamente a esa vida inventada, inventada como se inventa una novela o una obra de teatro, es a lo que el hombre llama vida humana, bienestar" (Ortega y Gasset 1964 334). 
ficción técnica y la naturaleza, sino entre una ficción técnica y otra, entre las muchas ficciones ${ }^{14}$.

Y es que nos encontramos en la misma embarazosa situación en que Epimeteo, el imprevisor (nomen est omen), había dejado a su hermano Prometeo.

Recordemos que Epimeteo, según Platón (Protágoras, 321a-322a), repartió entre todos los animales las facultades para sobrevivir y cuando le llegó su turno al hombre ya se le habían agotado, a Epimeteo no le quedaba ninguna atribución para la raza humana. Así que cuando Prometeo lo advirtió, hurtó a Hefesto y a Atenea su sabiduría técnica, necesaria para la vida. Tuvo que robar el fuego (nuestra luz eléctrica, la electricidad que conecta nuestro sistema nervioso con el mundo y lo electrifica), pero no le fue dado entrar en la Acrópolis, morada de Zeus, para conseguir lo que le hacía falta además de la sabiduría técnica, la sabiduría política. Y encima Prometeo hubo de sufrir atroz castigo...

Es dudoso que alguien pueda acceder a la morada divina, que pueda dar al hombre la sabiduría política, pero sí podemos decir algo en torno a la naturaleza de los valores, que nos permita al menos ubicarlos, buscarles un sitio. La única pista a nuestro alcance es que precisamente los valores no tienen ninguna naturaleza. No hay valores naturales. En efecto, quizá podamos reinterpretar el mito y figurarnos que si Prometeo no pudo robar la sapiencia política a Zeus, no fue ni por la altura de las murallas acropolitanas ni por sus olímpicos guardianes. Murallas y guardianes simbolizan más bien la custodia de la verdad más espantosa, la misma que se escondía-reinterpretando también el Génesis-en la prohibición de comer del Árbol de la sabiduría. A saber: que no hay valores "reales", los valores hay que fabricarlos con la sabia ficción técnica.

Si del ser o "realidad" no nos queda nada, tampoco nos podía quedar nada del valor. Vale decir, del valor natural. ${ }^{15} \mathrm{Y}$ si esto es así, si la época tecnológica no nos deja una naturaleza a la que adecuarnos, en la que encontrar la pauta de nuestro

${ }^{14}$ Quizá convenga aquí evocar de nuevo a I. Berlin enfatizando su constante enseñanza en torno a la pluralidad y no necesaria compatibilidad de los valores.

15 Cuando la modernidad ofreció una ética sin religión, no por ello renunció a concebir valores fundamentales, mantuvo la forma religiosa, la deuda infinita de la religión, bajo la especie del deber absoluto, algo aún más disciplinario al no darse ya la atenuación misericordiosa de la gracia divina. Del deber de la religión se pasó a la religión del deber, un deber que se autocomprendía como deber sin religión. Pero el valor sin Dios era una continuación de la religión por otros medios, los así llamados racionales. En efecto, la virtud laica no sólo prolongaba el orden axiológico fundamental, sino que lo reforzaba al independizar el cumplimiento del deber de cualquier tipo de compensación a posteriori: el deber es a priori. Queda eliminada toda optatividad con miras a un fin, cosa propia de morales antiguas, el deber no puede condicionarse a nada, sería dejarlo en un plano hipotético, someterlo a una espuria heteronomía, a un interés impuro. La moral pura, esto es, sin contaminación religiosa, es autónoma y, por tanto, su imperativo es categórico: el deber por el deber. Ese deber era un deber natural, no dictado ya por la también natural ley divina, sino por la naturaleza humana. Hoy—claro es—cuando la tecnología ha aliviado a la humanidad de la naturaleza, tanto exterior (física o divina) como interior o humana, "muertos" Dios y el hombre, ya no hay lugar para una moral natural. En una palabra: "hemos dejado de reconocer la obligación de unirnos a algo que no seamos nosotros mismos" (Lipovetsky 12). 
comportamiento, que nos proporcione una escala axiológica, entonces de nada sirven los intentos de nuestra tradición filosófica que pretendían encontrar una racionalidad que ante el hecho de que la técnica sólo sepa de medios para un resultado, medio a su vez para otro y así ad infinitum, rompiese esa cadena, ese mal infinito y estableciese los "auténticos" fines del hombre, una racionalidad que nos permitiese trazar una frontera entre lo humano y lo inhumano, que nos señalase el valor humano esencial con el que discernir el comportamiento inhumano, ese que es propio de los brutos, por una parte, y, por otra, de los más brutos todavía, los desalmados. Se pensaba que sin un plus de racionalidad sobre la racionalidad técnica de respuesta satisfactoria al medio hostil no era posible justificar la acción ética. Se trataba en definitiva de encontrar una racionalidad exclusivamente humana (aun cuando con pretensiones propias de la deidad) que superase el simple fin, compartido con los otros organismos, de la supervivencia, que exhibiese el fin naturalmente humano.

La aniquilación de la naturaleza "real" nos impide ya esa busca. Por supuesto, que aún habrá quien la lleve a cabo, pero ya no creeremos el resultado de su investigación. Siempre sospecharemos que aquello que llame "naturaleza humana objetiva" no sea sino un heterónimo de sus preferencias subjetivas, vale decir, un intento de extrapolación sinecdóquica de su modo particular de ser a modo universal y, en consecuencia, único, de ser humano. $Y$ no porque uno no pueda tener sus creencias o valores y querer compartirlos, o porque esos contenidos axiológicos sean inventos de ficción, sino por pretender pasar por real y único lo ficcional y plural, por querer tener la patente natural, una carta de naturaleza para imponerlos a los demás. La apelación a la naturaleza se convierte en una coartada para validar las acciones propias frente a las vituperables de los demás, lo cual en tanto conducta contra natura, si se restringe, censura, prohíbe o castiga, mejor que mejor, pues no se haría sino restablecer el "orden real" quebrantado. Los fanatismos, los fundamentalismos, los totalitarismos, los nacionalismos, en fin, todos aquellos extremismos, que están dispuestos a que triunfen sus valores "reales", aunque haya que sacrificar cruentamente la vida efectiva (preferiblemente la ajena mucho antes que la propia), siempre han afirmado tener a la naturaleza "real" de su parte.

Negar la coartada real o natural no significa, sin embargo, negar los valores, significa afirmar tan sólo que los valores no están en la naturaleza a la espera de ser descubiertos para que nos conformemos a/con ellos, es decir, que no hay realidad natural que nos haga o siquiera permita preferir unos valores a otros. El valor de la técnica es que los valores son a su vez técnicos, los valores son creaciones, artilugios, artefactos, máquinas: dispositivos ficcionales. Los valores son artificiales y justamente esto es lo que los hace más valiosos, pues siempre ha valido más el producto manufacturado que la materia prima. La manufactura lleva el sello de nuestra fragilidad, de nuestra caducidad, de nuestra finitud. Los valores son una fabulosa contingencia que en cualquier instante puede ser 
reemplazada por otra, por un disvalor para nosotros. Por eso, si creemos en la cultura de los derechos humanos, es porque nos reconocemos en ellos, y no porque ellos respondan a la "auténtica" naturaleza humana real, sino porque la fantaseamos así. La cultura de los derechos humanos es un producto precioso y muy delicado, que en cualquier momento se puede perder y que por ello, por razón de su exquisita rareza, conviene defender. Pero si llegase el malhadado día de su pérdida, no habría desaparecido ninguna parte inalienable e inviolable de la naturaleza humana (el mismo hecho de la desaparición descalificaría esos calificativos), sino un producto fictivo, seguramente el más hermoso, de la especie humana.

$\mathrm{Y}$ es que los valores no se adquieren por el conocimiento (Velle non discitur, repetía Séneca), no es cuestión de mayor sabiduría moral el obrar bien. Este prejuicio platónico, el intelectualismo socrático, es el responsable de que tradicionalmente se haya intentado una vez tras otra fundar la conducta moral. Pocas cosas menos democráticas y más estomagantes en el gremio filosófico que el desprecio del intelectual ante la conducta "inmoral" de los demás, que no son libres porque desconocen su propio yo, "pobrecitos", si se pusieran bajo la disciplina de su dominio, seguro que ya sabrían comportarse "libremente". Frente a la vieja fisura entre realidad y apariencias, a la que se remonta la escisión realidad/ficción, fisura que tanto ha valido para deshacerse de los "pseudohumanos", de los humanos meramente aparentes (por citar ejemplos del siglo pasado tan sólo: judíos en la Alemania de Hitler, comunistas en la España de Franco, españoles en la Euskal Herria de Otegi, burgueses en la Rusia de Stalin, musulmanes en la Gran Serbia de Milosevic, etc.), la técnica ha hecho añicos esa distinción, de modo que nos ha puesto en condiciones de prescindir de la realidad (por mucho que haya servido para hacerla operativa) y no para hacer ahora de las apariencias la realidad, sino para comprender que, suprimida la noción de "realidad", también desaparece la de meras "apariencias", El haber reducido el fundamento a nada, nos deja sin fundamento: ahora el fundamento es la nada a la que nos quieren reducir los fundamentalistas. Sin fundamento obviamente ya no podemos fundar el bien, pero, y esto es igual de obvio, aunque se olvida pronto, tampoco podemos fundar la violencia, sino que antes bien, podemos desarrollar sentimientos de piedad ${ }^{16}$ por los demás. Luego se trata

16 "Piedad" en el sentido compasivo, caritativo y hermenéutico que va de Schopenhauer a Vattimo, pasando por Dewey o Donald Davidson, y en los antípodas de la "perversión" o negación del otro de Gilles Deleuze, de un yo que quiere mermar la importancia del tú con la intención de preponderar él, intención, por lo demás, a la larga fracasada. De hecho, en el libro de conversación que, después de tantos años, logra reunir, gracias a la mediación de Santiago Zabala, a las cabezas más visibles del "pensamiento débil" y del "neopragmatismo", el discípulo de Davidson contrapone en su primera interlocución la caridad (a la que aquí apelamos con nuestra "razón retórica y democrática") al poder, a la razón autoritaria de la metafísica: "Ponerse fuera del lógos metafísico es casi lo mismo que cesar de buscar el poder y contentarse con la caridad. [...] Pienso en el declinar del lógos metafísico como un declinar en la intensidad de nuestro intento por participar en el 
de cambiar la pregunta, de dejar de lado la pregunta kantiana por lo que sea el hombre y sustituirla por la de la clase de mundo que podemos prepararles a nuestros sucesores, o la de los fines comunitarios que uno pueda perseguir (cf. Rorty, 2000b 16). De este modo uno deja de plantearse la cuestión esencialista de si los derechos humanos y los calabacines tienen distinto estatuto ontológico, para centrarse en la cuestión pragmatista de qué valores "fingir", de qué técnica axiológica crear para creer en nosotros.

Ahora bien, que los valores no se puedan fundamentar, que no puedan ser cimentados sobre una naturaleza o "realidad" suprimida técnicamente, no comporta que no se puedan argumentar, que no se puedan ofrecer razones. Eso lo pensaría el racionalista dispuesto a expedir cédulas de irracionalismo a quien no suscriba el suyo, el que tiene como modelo de razón a la razón suficiente, razón determinante, "mathética", demostrativa. Ciertamente, no tenemos un cálculo de los valores, un algoritmo axiológico. Pero si no podemos dar pruebas analíticas, sî podemos ofrecer, como quería Perelman, pruebas de esas que Aristóteles llamaba dialécticas, que-claro es-no tienen la unívoca contundencia de las otras, sino que ofrecen argumentos basados en la probabilidad, en la verosimilitud, en la plausibilidad, argumentos plurales. El propio Rorty argumenta a favor de los valores democráticos apelando a las razones del sentimiento moral, a la preferencia por los que son como nosotros y así repudian el sufrimiento ajeno, a la "lealtad ampliada"17. En cualquier caso, se trata de reclamar lo que Lipovetsky llama una "razón pragmática y experimental” (20), o lo que Blumenberg llamaba el "principio de razón insuficiente" 18 , la propuesta interpretativa basada en apreciaciones merecedoras de aceptación, o lo que Ortega había llamado la "razón histórica", que "es precisamente aquello que hasta ahora se ha llamado sinrazón” (1983a 621), para fingir los valores que nos configuren una vida en lugar de otra (la "realidad" es una, la ficción, múltiple), no algo mejor que la vida, sino una vida mejor.

$\mathrm{Y}$ es que la cuestión es que no tenemos criterios fuertes externos, una ortodoxia más allá de la simple doxa, que aplicar a nuestra historia, a las luchas de genes y "memes" para distinguir los buenos de los malos resultados. La evolución no tiene nada que ver con la evaluación. No hay conexión interna entre ambos expedientes, lo cual no nos impide que podamos, estimulados, por

poder y en la grandeza. La transición del poder a la caridad y la del lógos metafísico al pensamiento posmetafísico son ambas expresiones de una voluntad de aprovechar las oportunidades que se nos ofrecen, en lugar del intento de escapar de nuestra finitud alineándonos con un poder infinito" (Rorty, Vattimo, Zabala 86).

${ }^{17}$ Se trata de la noción de justicia como larger loyality (cf. Rorty 2000a, cuyo subtítulo es precisamente "Antiautoritarismo en epistemología y ética", o en otra traducción: "La justicia como lealtad ampliada" en Rorty 2002 79-99).

${ }^{18}$ Es difícil encontrar mejor apoyo a la tesis artificialista que se preconiza aquí sobre la necesaria carencia de valores naturales para un ser a quien le falta "lo más esencial", una "realidad", que las palabras de Blumenberg 1996b 124-125. 
ejemplo, por la "responsabilidad" de Jonas, comprometernos a no comprometer las condiciones para la supervivencia indefinida del animal humano en la tierra. Eso lo supo ver muy lúcidamente Dewey, quien, como Ortega, abandonó la noción de naturaleza humana ahistórica y la sustituyó por la idea de que ciertos mamíferos se han convertido recientemente en seres capaces de crear un nuevo medio para ellos mismos, en vez de simplemente reaccionar a exigencias ambientales. Y aunque rechazó que hubiese una conexión intrínseca o necesaria entre la racionalidad técnica y los valores democráticos, confió en que el desarrollo de las ciencias y las tecnologías aunara eficiencia y tolerancia, pues ahí estaba su utopía social y liberal: que la ficción técnica profundizara en la ruptura democrática con la vieja distinción entre el alto teórico y el bajo artesano, y que así abandonásemos la obsoleta cuestión acerca de la naturaleza humana para desacralizando, secularizando, desteleologizando la "realidad" y preocupándonos por rebajar el sufrimiento, fingirnos a nosotros mismos fabulándonos "como partes de un continuum al que pertenecen igualmente amebas y calamares, aunque también los más flexibles, libres e imaginativos humanoides que serán nuestros descendientes" (Rorty 1998 92).

Sin duda se entenderá mejor este planteamiento, cuya hipótesis de fondo es que la "ficción" no sólo no nos impide llegar a lo real, sino que es condición necesaria para ello, si dedicamos un breve espacio a reflexionar sobre la metáfora en Occidente. Ésta tradicionalmente se ha concebido como-por emplear analógicamente el conocido calificativo de Genette (1970) para la Retórica"metáfora restringida", como un elemento de adorno, algo decorativo, nunca substantivo, mera cuestión de lenguaje, nunca de pensamiento. Esto era algo que implícita o incluso explícitamente asumían las poéticas clásicas. Lo metafórico se sobreponía a lo conceptual para restarle sequedad y dureza, pero sin penetrar jamás en su núcleo. Toda metáfora, en último término, podía y pedía ser traducida a concepto. Es más, pasada la eventual emoción estética, lo valioso de lo literario era su filtrado racional, su destilado literal.

La noción de metáfora ha girado efectivamente en torno a la noción de "sustitución", como mera ficción o figura (forma sin contenido), algo no significativo o si acaso de significación vicaria, que alcanza su pleno significado cuando es reemplazado por su concepto propio, cuando se decanta su referente "real". Pero esta interpretación clásica de la metáfora es posible sólo si concebimos la semántica como aparte de la sintaxis y de la pragmática, si presuponemos la visión metafísica objetivista (o su pendant subjetivista). Sólo entonces se pueden reducir las representaciones a su función cognitiva. En cambio, nos inclinamos a favor del desplazamiento hacia el eje pragmático porque cualquiera que sea la manera en que nuestras representaciones "ficcionales" se vinculen a lo representado, la sanción de su alcance cognitivo reside antes que nada, más que en representar adecuadamente la "realidad" que modelizan, en el índice de éxito o fracaso de las interacciones futuras con la realidad. Así concebida la 
"representación", en términos de relaciones futuras con el mundo representado, queda desplazada la cuestión de la ficción del campo de la semántica de las representaciones al de su uso específico, con lo que el mundo figurado cambia con la propia figuración y la cuestión de la relación de la ficción con la realidad se hace una cuestión de índole eminentemente pragmática ${ }^{19}$. La "realidad" de referencia de la metáfora, aquello por lo que la metáfora está, lo que ésta "sustituye", forma parte también de la propia metáfora: no habría "realidad" sin catacresis ${ }^{20} \ldots$

En efecto, por lo que hemos estado observando con anterioridad, hemos de reconocer que la experiencia de la "realidad" no está exenta de una metafórica propia, que en nuestra experiencia los conceptos con que categorizamos están estructurados metafóricamente y, de consuno, la propia experiencia. Y si no lo reconocemos, pues también, ya que al asumir los presupuestos antes denunciados, y que, dichos ahora de otra manera, consisten en partir impremeditadamente de que los significados son objetivos, de que son objetos recibidos en las expresiones lingüísticas, las cuales son así pasivos recipientes, vasa fictilia, para los activos significados, ahí estaría latiendo ya toda una metafórica oculta.

Otra cosa es que al estar las metáforas ontológicas tan incardinadas en nuestra cultura (monedas gastadas que han perdido con el uso su cuño metafórico son los conceptos, apuntaba Nietzsche en su "inédito" Über Wabrheit und Lüge in aussermoralischen Sinn) no las percibamos como tales metáforas, sino como conceptos, como categorías "reales" (al igual que los que tenemos cierta edad nos quedamos tranquilos cuando se nos traduce a pesetas el valor en euros de un bien, como si el montante en pesetas ya indicase algo definitiva y cuádruplemente real, no otro término de estación, sino la estación término del tren conversor). No se trata de que cambiemos sin más-por usar la expresión de Lakoff y Johnson-las "metáforas mediante las que vivimos", sino de incidir precisamente en eso mismo: que vivimos mediante metáforas. Es decir, y una vez más, que nuestro pensamiento está estructurado metafóricamente, que no hay experiencia humana al margen de las metáforas. Y que, por tanto, las metáforas están a la base de cualquier operación de significado, de toda comprensión, de la semántica. Creer que hay un referente (realidad, naturaleza,

19 Asumimos la tesis de que el dispositivo ficcional se define no semántica, sino pragmáticamente (cf. Schaeffer 2012 182-215). Un enfoque digno de atención, en cuanto superador del encasillamiento semántico de la ficción por parte de la Filosofía analítica, ya desde Russell, mostrativo de cómo la semántica no se ha separado del todo de la epistemología, y de que la noción de "referencia" es un invento filosófico sin el cual los problemas acerca de la ficción simplemente dejan de suscitarse (de hecho, propone sustituir esa noción por la de talking about, radicalizando, como podríamos decir, el carácter secundario de la cuestión de la denotación de las proposiciones ficcionales en Searle, o la puesta entre paréntesis por parte de G. Genette de la cuestión del valor referencial de las representaciones inducidas por la ficción), se encuentra en Rorty 1996 182-216.

${ }^{20}$ En inglés, lo que recuerda el facta ficta nietzscheano, se utiliza incluso un término, a saber, faction, como combinación de facts y de fiction (cf. Lodge 298). 
unidad, literalidad, concepto, lógica) independiente de nuestras experiencias al que podemos acceder en toda su pureza es justo una creencia (mayor que la fe en el patrón oro o en las pesetas cuádruplemente "reales"), no algo demostrable conceptualmente, aceptable universalmente, natural, lógico, real.

De nuevo, hay que recalcar que esto no significa negar una "realidad" exterior, sino, antes al contrario, negar que nosotros seamos exteriores a la realidad: suponemos que hay cosas y que las cosas delimitan la experiencia ${ }^{21}$. En esto hay que ser "realista" u "objetivista", lo que ya es mucho suponer es que haya experiencia que medularmente no dependa de metáforas, de semejanzas ya no objetivas, inherentes a las cosas, sino interaccionales, pragmáticas, esto es, basadas en otras metáforas o conceptos metafóricos ${ }^{22}$.

$\mathrm{Y}$ aquí comparecen los valores como aquellas metáforas que, en tanto que "macrogestalts" experienciales, nos dicen lo que es "real", lo que es "bueno", cosa la cual es de vital importancia a tenor del primer valor, el de la propia supervivencia. Y que los valores no se hallen inscritos en la naturaleza "real", que no sean "objetivos", supone hacerlos solidarios de la experiencia de la contingencia humana, de la caducidad y mortalidad que nos son inevitables, y eso, que ya no dependan de una perspectiva "theorética", "mathemática", divina, es decir, su constitutiva fragilidad, es lo que los hace más valiosos, lo que hace que merezca la pena defenderlos, pues no existirán sino trópicamente, en la medida en que estemos dispuestos a sostenerlos. Y si esto es así, resulta que las metáforas, además de vehículos primarios del entendimiento, son en su virtualidad creadoras de nuevos significados, de nuevas pautas vitales o valores, fingidoras de realidad. De realidad humana. De realidad virtual. De realidad "ficticia".

Y aquí entran en juego las TICs y con antelación las ciencias mismas. Antes de ganarnos el anatema de Sokal23, hay que decir que las teorías einsteiniana de la relatividad, la heisenbergiana de la incertidumbre, la gödeliana de la incompletud, si es que no apoyan, no desmienten, desde luego, la debilidad de

21 Téngase en cuenta que las metáforas no surgen por generación espontánea, sino a partir de la interacción de nuestro cuerpo con los otros cuerpos, es decir, con el ambiente o medio físico, tienen que ver con la realidad, no puede ser menos si son "reales", sólo quien las interprete como meramente ficticias, en términos dualistas, creerá que proponemos su superposición obliteradora de lo "real".

${ }^{22}$ Y es que el todo es más "ficticio" que las partes (cf. Genette 199160 ).

23 En abril de 1996 Alain Sokal parodia el discurso postmoderno, que pretende apoyar sus argumentos políticos radicales en los resultados de la ciencia, logrando publicar en una revista de prestigio (Social Text) un texto desnudo de contenido ("Transgressing the Boundaries: Toward a Transformative Hermeneutics of Quantum Gravity"), cuya desnudez, como la imperial en el cuento de Andersen sobre "El traje nuevo del emperador", pasó desapercibida a editores y referees. Posteriormente revela su propia impostura y hace más explícita la crítica de autores como Deleuze y Guattari, Derrida, Latour, Irigaray, Lacan, Lyotard, Serres o Virilio, por apropiarse abusivamente de una terminología científica que no terminan de dominar como sustento de su vacuidad intelectual. 
la distinción clásica, objetivista, entre realidad y ficción. La imposibilidad de la etiquetación de un sistema, la limitación a una transparencia parcial en lugar de global, la insuperabilidad del finitismo están suficientemente acreditados. Y ¿qué decir de la teoría de las fractales de Mandelbrot, de la teoría del caos de Thom, de la teoría de las estructuras disipativas de Prigogine y de la investigación sinergética del caos de Haken? Estas teorías muestran-sin entrar en si demuestran o parten de ahí, pues no pretendemos apoyar esta posición en los datos de la ciencia, siempre dependientes de una teoría que los interprete, sino sólo enfatizar su no incompatibilidad con ella—que, por así decirlopermítase la osada metáfora-, la realidad presenta un perfil trópico, j"ficticio"!, es decir, que no "es" homogénea, sino heterogénea, que no es armónica, sino dramática, que no es unitaria, sino plural.

Y las nuevas tecnologías y especialmente las TICs afectan como ha sostenido, por ejemplo, Welsch, tanto a los presupuestos fácticos de la postmodernidad, como a su experiencia de la realidad (o de la irrealidad), como a su específica concepción del saber, como a su ontología (cf. 36-72). El fascinador hipertexto de Taylor y Saarinen Imagologies también es buena prueba de la convergencia entre la ontología postmoderna y la teleontología, de que ya no hay en la sociedad de la información hechos, sino "factoides", de que la "realidad" es más extraña que la ficción, de que lo sorprendente no es que lo real haya sido cuestionado, sino que haya permanecido tanto tiempo fuera de cuestión, de que toda realidad en tanto que mediática resulta virtual, de que en los mundos virtuales la ficción se hace realidad y la realidad se hace ficticia, de que "en realidad", lo ficticio es "irreal" por ser real...

$\mathrm{Y}$ aquí, en lo que Baudrillard ha denominado-no sin una cresta de resentimiento metafísico-el "estadio cibernético" de la realidad o "grado Xerox de la cultura" (16) , en la era digital en que se revela la indiscernibilidad entre el original y la copia, en que coinciden el eidos y el eikon, la idea y el icono, el modelo y la réplica, en que se realiza lo virtual y virtualiza lo real, en que se verifica el experimento antiplatónico del transhumano, del "animal aún no estabilizado", es donde se plantean los dilemas éticos ahora (cf. Bustamante). No se trata de adoptar una posición tecnófila o tecnófoba. El mundo contemporáneo en su conjunto no puede sencillamente sobrevivir sin las nuevas tecnologías (aunque tengan potencial suficiente para acabar varias veces con el mundo conocido). Las TICs se han convertido en un quasitranscendental y es inútil obviar esto, conforman ya una especie de inexcusable petitio principii de toda reflexión moral sobre ellas mismas, definen ya con independencia de nuestra voluntad su propio lugar de inteligencia, y pretender verlas desde fuera es una labor muy semejante a la del Barón de Münchausen, ese que pretendía salir de la charca en que había caído tirando del cabello al no lograrlo tirando del caballo.

Ahora bien, volviendo a la metáfora y a la distinción natural/ artificial o real/ ficticio, porque el mundo real no es objetivista no hay ninguna metáfora que 
agote la totalidad de la visión, toda metáfora al mismo tiempo que ilumina algo (al destacar ciertas conexiones o similitudes entre las cosas) oscurece (al preterir otras conexiones posibles), y lo oscurecido requiere, en consecuencia, de una nueva metáfora, la cual a su vez precisará de otra, y así en sucesivo juego de espejos, de espejismos. Los cuentos siempre se contaron en plural. Frente al monomito, valga el valor de la pluralidad. Y esto es algo que con las nuevas tecnologías se puede y suele olvidar... La reflexión ética ha de asumir el reto de iluminar esa frecuente postergación, por la cual se pretende otorgar a lo tecnológico las viejas propiedades de lo "real", momento en que la multiversalidad ficcional se transforma en universalidad real, en pensamiento único. He ahí el espacio discursivo del pensamiento moral, el del recuerdo de lo elemental: que los ordenadores no tienen cuerpo, ni sufren ni temen, no pueden tener experiencias humanas, luego no pueden constituir nuestra única metáfora. Ya Heidegger recordó que la técnica no consiste en el uso mayor o menor de aparatos, sino en una visión. Los dilemas axiológicos habrá que encararlos desde esta advertencia contra la mirada exclusiva y excluyente, impidiendo que la tecnología se convierta en grosero monóculo, en monstruoso cíclope que ose interrumpir la odisea humana.

\section{BIBLIOGRAFÍA}

Baudrillard, J. 2001. La transparencia del mal. Ensayo sobre los fenómenos extremos. Barcelona: Anagrama.

Berlin, I. 1998. The Crooked Timber of Humanity. Princeton: Princeton University Press. Blumenberg, H. 1996a. Arbeit am Mythos. Frankfurt: Suhrkamp.

Blumenberg, H.1996b. Wirklichkeiten in denen wir leben. Stuttgart: Reclam.

Bustamante, J. 1999. "Dilemas éticos en la sociedad de la información: apuntes para una discusión”, Argumentos de razón técnica 2:169-183.

Dennett, D.C. 1991. Consciousness Explained. Boston: Little.

Funuyama, F. 2002. El fin del hombre. Consecuencias de la revolución biotecnológica. Madrid: Ediciones B.

Galimberti, U. 1999. Psiche e techne. L'uomo nellétà della técnica. Milano: Feltrinelli.

Genette, G. 1970. “La rhétorique restreinte”. Communications 16:158-171.

Genette, G. 1991. Fiction et diction, Paris: Seuil.

Habermas, J. 2001. El futuro de la naturaleza humana. ¿̇Hacia una eugenesia liberal? Barcelona: Paidós.

James, W. 2000. Pragmatismo. Madrid: Alianza.

Jonas, H. 2003. Das Prinzip Verantwortung. Versuch einer Ethik für die technologische Zivilisation. Frankfurt: Suhrkamp.

Lakoff, G. \& M. Johnson. 1980. Metaphors We Live By. Chicago-London: University of Chicago Press.

Lipovetsky, G. 1994. El crepúsculo del deber. La ética indolora de los nuevos tiempos democráticos. Barcelona: Anagrama. 
Lodge, David. 1999. El arte de la ficción. Barcelona: Ediciones Península.

Marín-Casanova, J.A. 2004. Rumbo al mito. Giambattista Vico y la fabulosa retórica. Sevilla: Grupo Nacional de Editores.

Marín-Casanova, J.A. 2007. Las razones de la metáfora o el cancerbero de Vico. Sevilla: Grupo Nacional de Editores.

Marín-Casanova,J.A.2009. Contra natura. El desafío axiológico de las nuevas tecnologías. Sevilla: Paso-Parga.

Marquard, O. 1986. "Lob des Politheismus. Über Monomythie und Polymythie". Apologie des Zufälligen. Stuttgart: Reclam.

Ortega y Gasset, J. 1964. "Meditación de la técnica”. Obras Completas, vol. 5. Madrid: Revista de Occidente.

Ortega y Gasset, J. 1981. Unas lecciones de metafísica. Madrid: Alianza Editorial.

Ortega y Gasset, J. 1983a. "El mito allende la técnica". Obras Completas, vol. 9. Madrid: Alianza Editorial y Revista de Occidente.

Ortega y Gasset, J. 1983b. "Pidiendo un Goethe desde dentro". Obras completas, vol. 4. Madrid: Alianza Editorial y Revista de Occidente.

Ortega y Gasset, J. 1996. En torno a Galileo. Madrid. Espasa Calpe.

Perelman, C. \& L. Olbrechts-Tyteca. 1952. Rhétorique et philosophie: pour une théorie de l'argumentation en philosophie. Paris: P.U.F.

Perelman, C. \& L. Olbrechts-Tyteca. 2008. Traité de l'argumentation. La nouvelle Rhétorique. Bruxelles: Editions de l'Université de Bruxelles.

Petit, M. 2000. Elogio de la ficción. Madrid: Espasa Calpe.

PINKER, S. 2003. La tabla rasa. La negación moderna de la naturaleza humana. Barcelona: Paidós.

Putnam, H.1981. Reason, Truth and History. Cambridge: Cambridge University Press.

Riechmann, J. 2004. Gente que no quiere volar a Marte. Ensayos sobre ecología, ética y autolimitación. Madrid: Libros de la Catarata.

Rorty, R., G. Vattimo \& S. Zabala (compilador). 2006. El futuro de la religión. Solidaridad, caridad, ironía. Barcelona: Paidós.

Rorty, R. 1996. “¿Hay algún problema con el discurso de ficción?”. Consecuencias del pragmatismo. Madrid: Tecnos.

Rorty, R.1998. Pragmatismo y politica. Barcelona: Paidós.

Rorty, R. 2000a. "La justicia como una lealtad más amplia". El pragmatismo, una versión. Barcelona: Ariel.

Rorty, R. 2000b. Verdad y progreso. Escritos filosóficos 3. Barcelona: Paidós.

Rorty, R. 2002. Filosofía y futuro. Barcelona: Gedisa.

Scalfari, E. 1995. A la ricerca della morale perduta. Milano: Rizzoli.

Schaeffer, J.-M. 2002. ¿¿Por qué la ficción? Toledo: Ediciones Lengua de trapo.

Schaeffer, J.-M. 2012. "De la imaginación a la ficción”. Arte, objetos, ficción, cuerpo. Cuatro ensayos de Estética. Buenos Aires: Biblos.

Sokal, A. \& J. Bricmont. 1997. Impostures intellectueles. Paris: Jacob.

Taylor, M. \& E. SaArinen. 1994. Imagologies: Media Philosophy. London: Routledge.

Toynbee, A.J. 1985. Estudio de la Historia, I. Barcelona: Plantea. 
Vattimo, G. 1990. "El consumidor consumido". Casado, J. \& P. Agudíez. El sujeto europeo. Madrid: Editorial Pablo Iglesias.

Vattimo, G. 1996. Creer que se cree. Barcelona: Paidós.

VEGA, P. 2002. Frankensteiniana. La tragedia del hombre artificial. Madrid: Tecnos.

Welsch, W. 1991. "Die Postmoderne in Kunst und Philosophie und ihr Verhältnis zum technologischen Zeitalter". W.-Ch. ZimmerLi (Hrsg.), Technologisches Zeitalter oder Postmoderne? München: Wilhelm Fink Verlag. 
